\title{
The Use of Instagram as a Mobile-Assisted Language Learning Tool
}

\author{
Talip Gonulal \\ Erzincan Binali Yildirim University, Turkey \\ ORCID: 0000-0001-6441-4278
}

\begin{abstract}
The present study sought to explore how English language learners (ELLs) used Instagram, a popular social networking site, for language learning purposes and to reveal their attitudes towards and experiences in using it as a mobile-assisted language learning (MALL) tool. Special interest was also placed on whether there were any distinct ELL profiles in using Instagram for independent and informal language learning. In this mixed-methods study, both quantitative and qualitative data were concurrently collected through an online comprehensive survey consisting of three sections. Ninety-seven Instagram using ELLs took part in this study. Basic descriptive statistics and a cluster analysis were conducted on the quantitative data, and a thematic analysis on the qualitative data. The results showed that Instagram has the potential to help ELLs to improve overall language skills in general, and vocabulary and communication skills in particular. Further, ELLs' experiences in using Instagram as a MALL tool for informal language learning were largely positive. Additionally, two different language learner profiles (i.e., novice and experienced) emerged based on Instagram use habits and orientations. Overall, this study indicated that social networking platforms and MALL applications can be used as an effective mobile language learning tool.
\end{abstract}

Keywords: Social networking sites; Mobile-assisted language learning; English language learning; Instagram

\section{Introduction}

The use of internet and digital technology has become an inevitable part of daily life in the recent years. This increased use of and dependence on digital technology has influenced, to a greater or lesser extent, not only the lives of people but also the ways languages are learned and taught (Mazer, Murphy, \& Simonds, 2007). A current trend that combines digital technology and language learning is mobile-assisted language learning (MALL). MALL broadly refers to anytime, anywhere language learning activities undertaken through mobile devices without being limited to a physical location or a determined time (Kukulska-Hulme, 2009; Kukulska-Hulme \& Shiled, 2008). In line with this trend, several MALL apps (e.g., Duolingo, Babbel, Busuu, Wlingua and so forth) have slowly appeared as alternative language learning tools for those who want to learn languages in self-directed and informal ways.

In addition to MALL-oriented apps, common social networking platforms such as Facebook and Twitter have recently found their ways into MALL, as well. For instance, research provided evidence that Facebook (e.g., Alm, 2015; Kabilan, Ahmad, \& Abidin, 2010; Mitchell, 2012) and Twitter (e.g., Lomicka \& Lord, 2012; Solmaz, 2017; Taskiran, Gumusoglu, \& Aydin, 2018) have 
the potential to provide language learning opportunities by enabling language learners to interact in and through the target language. However, relatively few studies focused on Instagram despite the fact that it is one of the popular social networking platforms with effective MALL potentials. Further, there is limited research investigating the fully learner-led and selfdirected mobile language learning in informal settings outside of class because almost all studies looking at the language learning potentials of social networking platforms are either teacher-led or carried out as part of formal language learning. It is highly likely that learner profile, experience and motivation may vary when mobile language learning takes place in an informal and learner-led setting. Given that, the present study aimed to examine how English language learners (ELLs) used a popular social networking platform (i.e., Instagram) as a mobile language learning tool, particularly in informal learning settings, and whether any different learner profiles exist among ELLs. Further, ELLs' attitudes towards and experiences in using Instagram as a MALL tool for independent language learning were also explored.

\section{Literature Review}

The field of foreign and second language learning has witnessed a shift from the traditional language learning to a more technology-enhanced language learning over the last three decades (Chapelle, 1997; Golonka, Bowles, Frank, Richardson, \& Freynik, 2014). The integration of technology in language classrooms has been mostly welcomed since it can boost language learners' linguistic and digital competences by enhancing the language learning process and learner motivation. Motivation, a key element in the process of acquiring a new language (Dörnyei, 1994), warrants further attention and constitutes a crucial part when it comes to the integration of technology in language learning environments (Stockwell, 2013; Ushioda, 2011, 2013). For instance, Stockwell (2013) argues that there can be a bilateral relationship between technology use and the motivation in language learning. In other words, a learner with high motivation to use technology may develop motivation to learn a language. In the same way, a learner with high motivation to learn a language may want to utilize technology to reach his or her goals.

With the rapid development in technology and contemporary language learning methods, mobile devices (e.g., mobile phones, personal digital assistants [PDAs and tablet PCs]) have also found their way into formal and informal language learning. This new trend is broadly called mobile-assisted language learning (Kukulska-Hulme \& Shield, 2008). There are a number of affordances attributed to MALL in the literature. Spontaneity, individuality, flexibility, personalized and self-paced learning figure notably (Kukulska-Hulme, 2009, 2012). Arguably, one of the important characteristics of MALL is that it can take language learning out of the classroom and provide sustained language practice by enabling anytime, anywhere language learning. That is, contrary to more conventional and formal methods of learning, MALL provides opportunities for learning 'out in the world' (Brown, 2010, as cited in Kukulska-Hulme, 2012). For instance, watching a movie in the target language when travelling, listening to a foreignlanguage radio channel while going to work or playing language-related games while waiting for the bus are some examples of learning in the wild.

One popular way of language learning out in the world is to use social networking sites (SNSs) such as Facebook and Twitter. Although such SNSs are not designed specifically for MALL purposes, they can serve as an easy and useful venue for enhancing language learning and improving cultural awareness as well. For instance, Lee and Ranta (2014) argue that SNSs can provide opportunities for interaction between native speakers of English and ELLs, especially 
considering that it is quite challenging for English as a foreign language (EFL) learners to interact with native speakers outside the classroom. Given the language learning potentials of SNSs, a number of scholars (e.g., Al-Ali, 2014; Alm, 2015; Chartrand, 2012; Gamble \& Wilkins, 2014; Kabilan et al., 2010; Lee \& Ranta, 2014; Lomicka \& Lord, 2012, 2016; Mitchell, 2012; Solmaz, 2017,2018 ) have paid more attention to SNSs. As an example, Kabilan et al. (2010) conducted an attitudinal study with 300 Malaysian college students to examine the role of Facebook in English language learning. The results indicated that Facebook could be utilized as a useful tool to improve learners' English language skills, to increase learners' motivation to communicate in English, and to boost their confidence in practicing their English. In a similar vein, Mitchell (2012) attempted to explore ESOL learners' motivation for using Facebook as well as their Facebook use behaviors. Mitchell conducted a qualitative study with seven students attending an intensive English course at an American university. The results indicated that apart from social benefits such as making new friends or keeping in touch with existing friends, Facebook appeared to be an effective peripheral language learning tool. That is, almost all ESOL students reported that they improved their English language skills through using Facebook even though they did not intend to use it for language learning purposes. However, the only concern that was raised in the study was pertinent to the inaccurate and informal English language use on Facebook.

Similar perceptions and benefits were also reported when Twitter was employed in the English language learning environments (e.g., Kim, Park, \& Baek, 2011; Mompean \& Fouz-González, 2016; Taskiran et al., 2018). To illustrate, Taskiran et al. (2018) investigated Turkish EFL college students' perceptions regarding the use of Twitter in extra-curricular activities which were neither part of the curricula nor evaluated but guided by instructors. The results showed that Turkish EFL students perceived Twitter to be motivating and engaging. In addition, Twitter was reported to help improve overall language-learning skills, and grammar and vocabulary, in particular. In sum, the studies on Facebook and Twitter collectively suggested that they could be used as an effective mobile language learning tool.

Although there is a considerable body of research investigating the pedagogical functions of Facebook and Twitter, relatively little research to date has focused on the use of Instagram in English language learning. Especially considering that young generation are slowly migrating to Instagram from other popular SNSs (Lomicka \& Lord, 2016), it is important to examine the potentials of Instagram as a mobile language learning tool. As a photo- and video-sharing social media tool, Instagram was introduced in early October in 2010 and then became one of the most popular social networking platforms with 1 billion monthly active users as of June 2018 (Statistica, 2018a). In looking at the countries with the highest Instagram users, the United States is ranked first with 120 million monthly users, followed by India (67 million), Brazil (63 million), Indonesia (59 million) and Turkey (36 million; see Statistica, 2018b for further details).

Yet, despite its popularity, particularly among young adults, and its high potential for contextualized visual data, only a few scientific studies have so far examined the roles and functions of Instagram in language learning contexts. A rare example of this focus is Al-Ali's (2014) study. More specifically, Al-Ali explored the integration of Instagram in EFL classrooms as a mobile learning tool. In this teacher-led study, the primary focus was on speaking and writing skills. Al-Ali reported that Instagram provided unique opportunities to create more individualized learning experiences for language learners. In addition, Instagram was found quite effective in forming a strong sense of community among learners.

When viewed in its entirety, although the foci in previous SNS studies was to make language learning more learner-centered, they were predominantly teacher-led. In other words, teachers 
or instructors appeared to play a significant role, for instance, in asking learners to engage with the SNS under investigation. Conceived in this way, these SNS-based mobile language learning studies seem to belong more to teachers than learners. Given that, there is a lack of research on how social networking platforms can be effectively utilized in a fully learner-led format in informal language learning environment, which is as important as formal language learning environment. An emphasis on fully learner-led mobile language learning might lead to new learning perspectives and practices since a self-directed and self-paced mobile language learning might result in different learning experiences than a teacher-led mobile language learning in formal learning environment. Further, language learners who adopt self-instructed and informal mobile language learning might differ from other language learners who are more familiar with formal and teacher-led language learning. For instance, some mobile language learners might have a high degree of autonomy, motivation or digital literacy. Therefore, the primary purpose of this fully learner-led study was to examine the learner characteristics of a group of experienced Instagram using English language learners (ELLs), with a special focus on the extent to which they used it to improve their English language skills in informal learning settings. Another purpose was to explore ELLs' beliefs and experiences regarding the potentials of Instagram as a MALL tool. The following research questions guided the present study.

RQ1: What different profiles exist among English language learners in using Instagram as a MALL tool?

RQ2: What are English language learners' attitudes towards and experiences of using Instagram as a MALL tool?

\section{Method}

In this study, mixed-methods research design was chosen to answer the research questions. More specifically, a convergent parallel mixed-methods research design was used (Creswell \& Plano-Clark, 2011). That is, both quantitative and qualitative data were concurrently collected but analyzed separately. Then, the results were merged and interpreted collectively. This method was the most suitable one to better explore distinct Instagram user profiles and the potentials of Instagram as a MALL tool for informal learning.

\section{Instrument}

A survey consisting of three parts was used to collect data (see Appendix A). The first part included 15 questions addressing background information and Instagram use habits. The second part was a 6-point Likert-type scale developed by the researcher following Kabilan et al.'s (2010) and Gamble and Wilkins' (2014) questionnaires on learners' perceptions of Facebook. This scale initially included 18 statements addressing learners' perceptions of and attitudes towards using Instagram as a language learning tool. After consulting with two selected experts, several changes and edits were made, and the final version consisted of 15 statements. The Cronbach's alpha level was .94, which was quite high and therefore suitable for data collection (Dörnyei \& Taguchi 2009; Field, 2013). Finally, the last part of the survey included three open-ended questions to further explore learners' views of MALL in general, and Instagram as a MALL tool in particular. 


\section{Procedures}

Since the study targeted Instagram users who used it for English language learning purposes, the first step was to identify the potential participants. Thus, several tags (e.g., \#englishlanguage, \#learnenglish, \#englishlesson) were searched on Instagram to locate the groups which learners follow to improve their English language skills. Then, an online version of the survey was created using Qualtrics survey tool, and the survey link was sent to the followers of groups devoted to English language learning and teaching. Further, survey circle website was also used to reach more eligible participants who could take the survey. The data collection period lasted 8 weeks.

\section{Participants}

One hundred and twenty-eight participants initially took part in the present study. However, 26 participants did not answer any questions on the survey and therefore did not provide any data. Further, 5 more participants were excluded from the analyses because they reported that they had very little experience (i.e., less than a month) in using Instagram since they had recently created their Instagram accounts. After excluding those participants, the total number of participants were reduced to 97 (33 males and 64 females) users of Instagram. Participants were all experienced users. That is, almost half of them (51\%) had been using Instagram for 3 to 7 years and about a quarter (25\%) 1 to 2 years. Further, a great majority of the participants (81\%) reported using Instagram on a daily basis. More specifically, participants reported spending almost two hours on Instagram on average $(M=1.88, S D=1.73)$ for educational and leisure purposes. Additionally, more than half (53\%) of participants' communication on Instagram (e.g., sharing a post, commenting on a post, sending and replying messages) was solely in English. Further, a quarter of participants' followings on Instagram was related to English language per se (e.g., an English idioms page).

Participants' self-rated English language proficiency indicated that no skill averaged below 4 out of 6 , with reading being the highest $(\mathrm{M}=4.93, \mathrm{SD}=1.26,95 \% \mathrm{Cl}[4.66,5.19])$ and speaking being the lowest $(\mathrm{M}=4.32, \mathrm{SD}=1.52,95 \% \mathrm{Cl}[4.08,4.68])$. Participants were mostly adult learners in that the mean age was 26 years old $(S D=7.52$ ). In addition, participants were coming from 42 different countries: Brazil (8); Turkey (7); Finland, Germany (6); Azerbaijan, Indonesia, Iran, Spain, Ukraine (5); China, India, Russia (3); France, Hungary, Italy, Japan, Kazakhstan, Netherlands, USA (2); Albania, Algeria, Armenia, Belarus, Czech Republic, Egypt, Greece, Iraq, Kenya, Lithuania, Malaysia, Moldova, Poland, Portugal, Puerto Rico, Serbia, Sudan, Syria, Taiwan, Tajikistan, Thailand, and Venezuela (1). Most frequent first languages were Russian, Portuguese, Turkish, Spanish, German, Finnish and Arabic. Participants were majoring in a variety of disciplines (e.g., TESOL, linguistics, accounting, engineering, psychology, sociology, pharmacy, medicine and so on), with majority (35\%) in TESOL, linguistics or English-related programs. Further, most participants were in either MA (31\%) or PhD (13\%) programs or just earned their BA degrees (11\%).

\section{Analysis}

Frequencies, percentages and other basic descriptive statistics were calculated to analyze the results of the background questionnaire, learners' Instagram use habits and orientations, and their attitudes towards Instagram as a MALL tool. As a routine data screening procedure, before performing any statistical tests, the data went through a comprehensive missing value analysis 
(MVA). The MVA results showed that 75 participants (77\%) completed all the items on the questionnaire whereas 22 participants (23\%) missed some items. In looking at the rate of missing values, $7 \%(n=226)$ was missing out of the total values $(n=2,878)$ on the survey. Considering that the proportion of missing data was larger than the suggested cut-off level (i.e., 5\%; see Gonulal, 2019 and Schafer \& Graham, 2002), multiple imputation method was used to remedy the missing data issue. In the multiple imputation method, the data were imputed 5 times and then the returned estimates were averaged.

In order to identify any distinct Instagram user profiles, a cluster analysis was run. The purpose of cluster analysis is "to create a new categorical variable that minimizes the amount of variation within categories, while maximizing the differences among categories" (Staples \& Biber, 2015, p. 243). Simply put, cluster analysis is highly effective in identifying homogenous clusters or groups in a dataset. Given the exploratory nature of this study, a hierarchical cluster analysis (HCA) was conducted in that there was no prior expectation regarding the number and characteristics of the clusters. The HCA was performed on SPSS 21.0, with the following suggested options selected: agglomeration schedule-Ward's method-squared Euclidean distance. After the identification of clusters, basic descriptive statistics, 95\% confidence intervals, independent t-tests and Mann-Whitney $U$ tests were calculated to compare the clusters. Since multiple comparisons were made between the clusters, a Bonferroni correction was applied to decrease Type 1 error. Therefore, the new adjusted alpha level was .01 (i.e., $.05 / 5)$. Finally, for the qualitative data, a thematic analysis was conducted.

\section{Results}

\section{Instagram User Profiles}

The first research question focused specifically on whether there would be distinct user profiles in terms of using the application as a MALL tool. The hierarchical cluster analysis suggested a two-cluster solution, which is illustrated in the dendrogram (see Appendix B). However, since it is also highly suggested to examine the distances between the clusters (i.e., the fusion coefficients) to determine the optimal number of clusters (Staples \& Biber, 2015), an examination of the distance between the coefficients indicated that a two-cluster solution was the better cluster model.

The results of the two-cluster analysis showed that Cluster 1 consists of 46 ELLs (16 males and 30 females) and Cluster 251 ELLs (17 males and 34 females). Cluster $1(M=27.51, S D=7.87)$ and Cluster $2(\mathrm{M}=25.16, \mathrm{SD}=7.09)$ were almost identical in age, $\mathrm{t}(95)=1.541, \mathrm{p}=.127$. Cluster 1 were mostly in their senior year (20\%), in their MA $(37 \%)$ or PhD (13\%) program. Likewise, Cluster 2 were also mostly in their senior year (22\%), in their MA (26\%) or PhD (12\%) program. Additionally, Cluster 1 and Cluster 2 did not statistically differ in their self-rated English proficiency, $\mathrm{t}(95)=.705, \mathrm{p}=.483$. However, there are some differences between Cluster 1 and Cluster 2 in terms of their Instagram use habits and orientations. For example, only $24 \%$ of Cluster 1 used the Instagram application in English whereas the rate was 77\% in Cluster 2. In regards to the length of Instagram use, there were no striking differences but it might be noted that there were more experienced Instagram users (i.e., using Instagram at least for 5 years) in Cluster 2 (20\%) than in Cluster 1 (11\%). 
CONTEMPORARY EDUCATIONAL TECHNOLOGY, 2019, 10(3), 309-323

DOI: https://doi.org/10.30935/cet.590108 - TYPE: Research Article

Table 1. Comparison of ELLs' Instagram Use Habits and Orientations by Cluster Membership

\begin{tabular}{|c|c|c|c|c|c|c|c|c|}
\hline & \multicolumn{3}{|c|}{ Cluster 1} & \multicolumn{3}{|c|}{ Cluster 2} & \multicolumn{2}{|c|}{$\begin{array}{c}\text { Mann-Whitney U } \\
\text { Test }\end{array}$} \\
\hline & M & SD & $95 \% \mathrm{Cl}$ & $M$ & SD & $95 \% \mathrm{Cl}$ & U & $p$ \\
\hline $\begin{array}{l}\text { Time spent on } \\
\text { Instagram (hrs.) }\end{array}$ & 1.29 & 1.09 & $\begin{array}{l}{[.96,} \\
1.62]\end{array}$ & 2.41 & 2.03 & $\begin{array}{l}{[1.84,} \\
2.98]\end{array}$ & 1.595 & .002 \\
\hline $\begin{array}{l}\text { Communication in } \\
\text { English (\%) }\end{array}$ & 30.02 & 27.99 & $\begin{array}{l}{[21.61,} \\
38.43]\end{array}$ & 57.35 & 24.19 & $\begin{array}{l}{[50.54,} \\
64.15]\end{array}$ & 1.856 & .001 \\
\hline $\begin{array}{l}\text { Language content } \\
\text { followed (\%) }\end{array}$ & 13.20 & 16.68 & $\begin{array}{l}{[8.18,} \\
18.21]\end{array}$ & 36.19 & 29.10 & $\begin{array}{l}{[28.01,} \\
44.38]\end{array}$ & 1.717 & .001 \\
\hline
\end{tabular}

Further, almost all the members of Cluster 2 appeared to be an ardent daily user of Instagram as a MALL tool (see Table 1 ). Indeed, Cluster 2 reported using Instagram approximately two and half hours on average (SD $=2.03$ ) whereas Cluster 1's average time of Instagram use was around one hour ( $S D=1.09)$. This difference was statistically significant $(U=1.595, p=.002)$. In the same vein, Cluster 2 reported that the majority (57\%) of their communication in Instagram was in English. On the other hand, only 30\% of Cluster 1's communication was in English. This difference was also statistically significant $(U=1.856, p<.001)$. Similarly, Cluster 2 seemed to significantly follow more English-related posts, pages, groups and so forth on Instagram when compared to Cluster $1(\mathrm{U}=1.717, \mathrm{p}<.001)$. Overall, in looking at the Instagram use orientations and habits of Cluster 1 and Cluster 2, it is obvious that Cluster 1 is at a low level in terms of using Instagram for English language learning purposes while Cluster 2 is at a higher level. Put it another way, members in Cluster 1 are novice but members in Cluster 2 are experienced users of Instagram as a MALL tool.

\section{Attitudes Towards and Experiences of Using Instagram as a MALL Tool}

The second research question dealt with ELLs' attitudes towards and perceptions of using Instagram for English language learning purposes (see Table 2). Both Likert-scale and openended questions were used to answer this research question. Descriptive statistics for the Instagram attitude questionnaire are presented in Table 2. Overall, ELLs had relatively positive attitudes towards the use of Instagram for language learning purposes $(M=4.21$ out of $6, S D=$ .78). When looking more closely at the potential educational use of Instagram, ELLs largely perceived that Instagram can be a good platform to learn new English words ( $M=4.86, S D=.95$ ) and to read in English $(M=4.82, S D=.99)$. Similarly, ELLs considered Instagram suitable for improving English communication skills $(\mathrm{M}=4.46, \mathrm{SD}=.96)$.

Further, ELLs believed that Instagram has the potential to make learning English a fun activity $(M=4.69, S D=1.09)$, to motivate learners to read more English-related materials ( $M=4.45, S D$ $=1.09)$, and to motivate learners to communicate more using English ( $M=4.42, S D=1.30)$. On the other hand, ELLs had marginally negative perceptions of using Instagram to improve English grammar knowledge $(M=3.81, S D=1.31)$ or to overcome language mistakes $(M=3.45, S D=$ 1.19). Additionally, ELLs considered that Instagram should not be the only, or rather, main source of learning English $(M=3.93, S D=1.24)$ but it might be used as a peripheral language learning tool. 
Table 2. Descriptive Statistics for ELLs' Attitudes towards and Perceptions of Using Instagram

\begin{tabular}{lccc}
\hline & $\mathrm{M}$ & $\mathrm{SD}$ & $95 \% \mathrm{Cl}$ \\
\hline 6. Instagram is a good platform to learn new words in English & 4.86 & .95 & {$[4.67,5.05]$} \\
3. Instagram is a good platform to read in English & 4.82 & .99 & {$[4.62,5.02]$} \\
10. Instagram makes learning English more interesting & 4.69 & 1.09 & {$[4.47,4.91]$} \\
4. Instagram is a good platform to develop English communication & 4.46 & .96 & {$[4.26,4.65]$} \\
& 4.45 & 1.09 & {$[4.23,4.67]$} \\
skills & 4.42 & 1.30 & {$[4.16,4.69]$} \\
13. Instagram increases my motivation to read English materials & 4.27 & 1.12 & {$[4.05,4.50]$} \\
12. Instagram increases my motivation to communicate using English & 4.26 & 1.28 & {$[4.00,4.52]$} \\
11. Instagram makes learning English easier & & & \\
14. Instagram increases my motivation to write in English & 4.20 & 1.13 & {$[3.97,4.42]$} \\
1. Instagram is suitable for educational purposes & 4.16 & .96 & {$[3.97,4.36]$} \\
8. Instagram is a good platform to improve overall English skills & 4.11 & 1.21 & {$[3.86,4.35]$} \\
9. Instagram is a good platform to reach authentic English materials & 4.06 & 1.13 & {$[3.83,4.29]$} \\
2. Instagram is a good platform to practice writing in English & 3.93 & 1.24 & {$[3.68,4.18]$} \\
15. Instagram encourages me to spend more time learning English & 3.81 & 1.31 & {$[3.55,4.07]$} \\
7. Instagram is a good platform to improve English grammar & & & \\
knowledge & 3.45 & 1.19 & {$[3.21,3.69]$} \\
5. Instagram is a good platform to overcome language mistakes & & &
\end{tabular}

Note. $1=$ strongly disagree, 6 = strongly agree.

In addition to the scale data, the open-ended questions were also analyzed. Forty-nine participants answered the open-ended questions at the end of the survey and shared their opinions, attitudes and experiences regarding the use of Instagram as a mobile English language learning tool. Participants' responses generated 3,102 words of quantitative data. As can be seen in Table 3, a thematic analysis revealed five broad yet mostly interrelated themes: (a) practicing English, (b) improving vocabulary knowledge, (c) reaching native speakers, (d) interesting language learning experience, and (e) informal language use. Although the majority of the themes address the positive and advantageous aspects of Instagram, a non-ignorable portion also highlighted the disadvantages linked to the use of Instagram.

Table 3. The List of Themes Generated in the Qualitative Data

\begin{tabular}{lcc}
\hline Themes & Frequency & $\%$ \\
\hline Practicing English & 14 & 26.4 \\
Improving vocabulary knowledge & 13 & 24.5 \\
Reaching native speakers & 10 & 18.9 \\
Interesting language learning experience & 9 & 17.0 \\
Informal language use & 7 & 13.2 \\
\hline
\end{tabular}

The first theme concerns the opportunities Instagram offers to ELLs to practice their English in general. For instance, an Indonesian learner of English highlighted this important functionality of Instagram in EFL settings stating that "I learned English from elementary school till college, but I can't speak English very well, because I don't have much chance to practice my English except in English class. That's why I think Instagram is a great way to improve my overall English skills and to find people to practice my English." Additionally, a Puerto Rican learner highlighted a similar point: "It mainly gives me the opportunity to practice my language skills that I can't practice any other way since I live in a Spanish-speaking island." In the same vein, a Spanish learner of English elaborated on the opportunities that Instagram offers to ELLs stating that "since you are having real conversations and interactions with real people from the rest of the world, I think that it's an outstanding way of practicing English." 
The second theme relates to one particular aspect of language learning. To put it another way, Instagram is reported to help ELLs improve their vocabulary knowledge. For instance, an Indian learner explained how he used Instagram to learn new words in English: "I have followed many pages and they daily upload a new word along with its meaning and how to use that word appropriately in real life." Several participants also commented on why Instagram could be an ideal way to learn new vocabulary. To illustrate, an Italian learner stated that "the association of images to words makes it easier for learners to learn new vocabulary more efficiently."

Another theme that emerged from the qualitative data is pertinent to the effectiveness of Instagram in helping ELLs reach more native speakers or advanced speakers of English to practice their communication skills. A Venezuelan learner mentioned that "I have been using Instagram since 2015 to follow native speakers and non-native English teachers". A Russian learner stated that "it helps me communicate with more native speakers of English. This is an effective way to improve conversational skills." In a slightly different vein, a Brazilian learner stated that "My native speaker friends on Instagram help me learn new ways to express my feelings."

The fourth theme concerns the ways Instagram can make English language learning experience more interesting and fun. A Portuguese learner pointed out that "Instagram certainly has the element of combining pictures with texts, which can be very helpful. Also, it's a way of making learning more fun and relatable to the students." A Spanish learner "I think it's a great way to make language learning as practical, fun and authentic. It can increase students' motivation and exigencies to communicate in English. It gives students access to so many different cultural aspects."

Contrary to the previous themes, the last theme addresses that Instagram might not be an ideal platform to improve English skills, in particular grammar knowledge simply because slang or inappropriate English use is pretty common on Instagram. As an example, an Indonesian learner expressed that "it will be disadvantageous in learning grammar because not every Instagram users and accounts display accurate grammar." Likewise, a Finnish learner also highlighted the very same point: "The English language used on Instagram is not always proper or grammatically correct, so I don't think it is good for this purpose." If English learners do not be careful when choosing the pages to follow to improve their English, Instagram may do more harm than good. Regarding this point, an Italian learner explained that "I think it motivates to learn but it might be backfiring because the English learned there is no formal language."

\section{Discussion and Conclusion}

Studies looking at mobile language learning within a fully learner-led and informal setting are relatively rare. As an initial foray into this type of mobile language learning research, the primary purposes of the current study conducted with experienced Instagram end-users were (a) to reveal ELLs' Instagram use habits for educational purposes and identify any distinct profiles among ELLs when using Instagram as a MALL tool, and (b) to investigate ELLs' opinions and experiences regarding the employment of Instagram as a MALL tool. The quantitative and qualitative data gathered from a diverse group of Instagram using English learners revealed some important findings.

Even though Instagram per se was not designed for use as an educational application, most ELLs reported that they were actively used it for English language learning purposes. Similarly, using 
social networking platforms for such purposes were also examined or reported in other studies (e.g., Lomicka \& Lord, 2012; Mitchell, 2012). Further, a great majority of ELLs detailed different methods of utilizing Instagram as a mobile language learning tool. To illustrate, almost half of ELLs pointed out that they strived to use only English when communicating (e.g., posting a comment, replying and sending direct messages) on Instagram. Additionally, another trend in Instagram use that figured remarkably among ELLs was to follow and make use of certain Instagram pages devoted to English language development (e.g., BBC learning English, daily English learning, English online coach, learn English myself).

First, the cluster analysis uncovered two similar yet different groups of Instagram-as-a-mobilelanguage-learning users. Although both groups considered Instagram as an effective way of improving English language skills, they differed in their Instagram use habits and orientations. Most notably, Cluster 2 appeared to be more experienced and passionate Instagram users than Cluster 1. For instance, Cluster 2 tended to spend considerably more time on Instagram, exclusively use English to interact with other people and subscribe to noticeably more Englishrelated pages and groups on Instagram, and reported to use or have used other MALL tools (e.g., Duolingo) and social networking platforms (e.g., Facebook and Twitter) to improve their English proficiency. That is, members in Cluster 2 are arguably more technology-savvy. On the other hand, Cluster 1 seem to be highly determined to improve their English skills by making use of the readily available tools such as Instagram even if their digital literacy levels were on the middle ground. This means that there is a relationship between the use of technology and the increased language learning motivation (as in Cluster 2), and between the high language learning motivation and the increased use of technology (as in Cluster 1).

As far as the literature review suggests there are no published studies with which to compare this finding directly. However, a few scholars (e.g., Stockwell, 2013; Ushioda, 2011, 2013) have drawn attention to this point. For instance, Stockwell (2013) clearly noted that "motivation to use a technology could very well lead learners to develop motivation to learn a language (although unlikely automatically) and, conversely, sustained motivation to learn a language could result in a desire to use technology" (p. 163). In a similar way, Ushioda (2013) put forward that thanks to intrinsic characteristics of mobile learning such as flexibility, freedom and autonomy, "internalised motivation for independent learning" can be promoted (p. 2). Overall, this finding suggests that a bi-directional relationship between technology use and language learning motivation is possible.

The second purpose of the current study was to explore ELL's attitudes towards and experiences in using Instagram for informal language learning. ELLs' overall attitudes towards using Instagram for language learning purposes were largely positive due to its suitability for sustained English language learning. Further, ELLs mostly considered Instagram to be a motivating and interesting mobile language learning tool. To be more specific, Instagram appeared to motivate ELLs to read enjoyable materials including authentic language use, and to use the target language more often. Some other affordances Instagram offers to English learners are that it can be a great venue for vocabulary development thanks to its suitability for contextualizing text with visual data. Indeed, several ELLs explicitly stated in the open-ended questions section that they particularly used the application to improve their vocabulary knowledge. This inclination among the ELLs is in line with the other SNS studies of similar nature (e.g., Alm, 2015; Kabilan et al., 2010; Taskiran et al., 2018), which reported that such social networking platforms can serve an ideal place to learn and practice new words. 
Furthermore, based both on the quantitative and the qualitative data, there seemed to be almost a consensus among the ELLs that Instagram is an easy and convenient way of improving overall communication skills simply because it promotes a sense of community where ELLs can have the opportunity to interact and socialize with other ELLs, and provides ELLs with an opportunity to readily reach and communicate with native speakers or advanced speakers of English synchronously or asynchronously. Similar affordances were also highlighted in other SNS studies (e.g., Blattner \& Fiori, 2009; Lee \& Ranta, 2014; Mitchell, 2012; Solmaz, 2017). As an example, Blattner and Fiori (2009) reported that "...[Facebook] develop relationships with native speakers who share similar interests and who will interact on a regular basis in L2" (p. 22). Apropos of this particular affordance, Instagram and other social networking platforms can be a valuable source for English as a foreign language learning contexts where it can be quite challenging to interact with native speakers or speakers with good command of English.

Using Instagram as a mobile language learning tool is, of course, not without issues. One drawback that was frequently expressed especially in the qualitative data concerns the prevalence of informal language used on Instagram. Therefore, a number of ELLs had relatively negative attitudes towards utilizing the application to improve grammar knowledge or to overcome structure-related mistakes. Given that, several ELLs suggested that Instagram should not be the sole way of learning English in an informal way but can be a peripheral language learning tool. In looking at other similar social networking studies (e.g., Mitchell, 2012), the same issue has been reported. Another potential problem with Instagram is that it may not be an optimal mobile language learning method for contents or skills that are more cognitively demanding. In such cases, learners might need well-designed mobile learning applications and even larger digital devices.

Before concluding, it is important to note that there are several limitations that should be kept in mind. First, even though the sample is considered to be representative of ELLs, a larger sample size might have yielded more generalizable findings. However, considering the nature and the focus of this study, the current sample size was adequate enough to provide reliable and significant results. Second, only one type of social networking platforms was examined in this study. It is likely that ELLs, especially those with higher levels of digital literacy, might use other sites (e.g., Twitter and Facebook) or mobile-assisted language learning tools (e.g., Duolingo, Babbel, and Busuu) in different and effective ways. Third, this small-scale study adapted a brief questionnaire in order to reach more experienced Instagram users. Future studies might use a more comprehensive survey to better measure language learners' mobile language learning orientations and habits. Further, MALL-oriented researchers might do well to focus on the relationship between learner motivation and autonomy, and the use of MALL tools for long-term language learning.

Yet, in spite of these limitations, the current study shed light on the fully learner-initiated andled mobile language learning in informal settings, an area that we know so little about. In doing so, the current study showed that when used as a MALL tool, Instagram, and probably other similar social networking sites, have the potential to help language learners to improve overall language skills in general, and vocabulary and communication skills in particular, probably because social networking platforms can be readily utilized anywhere, anytime to increase the amount of input and output in the target language. Although English language learners' experiences in using Instagram as an informal language learning tool were largely positive, some concerns were raised regarding that Instagram can also be appropriate to employ in formal language learning contexts probably because Instagram was not specially designed for educational purposes. Although social networking sites may not serve as panacea for language 
learning and teaching issues, they can serve as a bridge between formal and informal language learning environments (Kukulska-Hulme, 2009) or as an effective peripheral language learning tool. Therefore, language teachers might consider supporting language learners to use available MALL applications and social networking platforms as a language learning tool so that their exposure to the target language can be sustained even outside the classroom.

\section{References}

Al-Ali, S. (2014). Embracing the selfie craze: Exploring the possible use of Instagram as a language mLearning tool. Issues and Trends in Educational Technology, 2(2), 1-16.

Alm, A. (2015). "Facebook" for Informal Language Learning: Perspectives from Tertiary Language Students. The EuroCALL Review, 23(2), 3-18.

Blattner, G. \& Fiori, M. (2009). Facebook in the language classroom: Promises and possibilities. International Journal of Instructional Technology and Distance Learning, 6(1), 17-28.

Chapelle, C. (1997). CALL in the year 2000: Still in search of research paradigms? Language Learning \& Technology, 1(1), 21-35.

Chartrand, R. (2012). Social networking for language learners: Creating meaningful output with Web 2.0 tools. Knowledge Management \& E-Learning, 4(1), 97-101.

Creswell, J. W. \& Plano Clark, V. L. (2011). Designing and conducting mixed methods research (2nd ed.). Los Angeles: SAGE Publications.

Dörnyei, Z. (1994). Motivation and motivating in the foreign language classroom. Modern Language Journal, 78(3), 273-284.

Dörnyei, Z. \& Taguchi, T. (2009). Questionnaires in second language research: Construction, administration, and processing. London: Routledge.

Field, A. (2013). Discovering statistics using IBM SPSS statistics. London: Sage.

Gamble, C. \& Wilkins, M. (2014). Student attitudes and perceptions of using Facebook for language learning. Dimension, 49-72. doi: 10.7763/IJIET.2016.V6.820

Golonka, E. M., Bowles, A. R., Frank, V. M., Richardson, D. L., \& Freynik, S. (2014). Technologies for foreign language learning: a review of technology types and their effectiveness. Computer Assisted Language Learning, 27(1), 70-105.

Gonulal, T. (2019). Missing data management practices in $L 2$ research: The good, the bad and the ugly. Erzincan University Education Faculty Journal, 21(1), 1-18.

Kabilan, M. K., Ahmad, N., \& Abidin, M. J. Z. (2010). Facebook: An online environment for learning of English in institutions of higher education? The Internet and Higher Education, 13(4), 179-187.

Kim, E. Y., Park, S. M., \& Baek, S. H. (2011). Twitter and implications for its use in EFL learning. Multimedia Assisted Language Learning, 14(2), 113-137.

Kukulska-Hulme, A. (2009). Will mobile learning change language learning? ReCALL, 21(2), 157165.

Kukulska-Hulme, A. (2012). Mobile-assisted language learning. In C. Chapelle (Ed.), The encyclopedia of applied linguistics (pp. 3701-3709). New York: Wiley. 
Kukulska-Hulme, A. \& Shield, L. (2008). An overview of mobile assisted language learning: From content delivery to supported collaboration and interaction. ReCALL, 20(3), 271-289.

Lee, K. \& Ranta, L. (2014). Facebook: Facilitating social access and language acquisition for international students? TESL Canada Journal, 31(2), 22-50.

Lomicka, L. \& Lord, G. (2012). A tale of tweets: Analyzing microblogging among language learners. System, 40(1), 48-63.

Lomicka, L. \& Lord, G. (2016). Social networking and language learning. In F. Farr, \& L. Murray (Eds.), The Routledge handbook of language learning and technology (pp. 255-268). New York, NY: Routledge.

Mazer, J. P., Murphy, R. E., \& Simonds, C. J. (2007). I'll see you on "Facebook": The effects of computer-mediated teacher self-disclosure on student motivation, affective learning, and classroom climate. Communication Education, 56(1), 1-17.

Mitchell, K. (2012). A social tool: Why and how ESOL students use Facebook. Calico Journal, 29(3), 471-493.

Mompean, J. A. \& Fouz-González, J. (2016). Twitter-based EFL pronunciation instruction. Language Learning \& Technology, 20 (1), 166-190.

Schafer, J. L. \& Graham, J. W. (2002). Missing data: our view of the state of the art. Psychological Methods, 7(2), 147-177.

Solmaz, O. (2017). Autonomous language learning on Twitter: Performing affiliation with target language users through\# hashtags. Journal of Language and Linguistic Studies, 13(2), 204-220.

Solmaz, O. (2018). A critical review of research on social networking sites in language teaching and learning. Contemporary Educational Technology, 9(3), 315-330.

Staples, S. \& Biber, D. (2015). Cluster analysis. In Plonsky, L. (Ed), Advancing quantitative methods in second language research. New York: Routledge.

Statistica (2018a). Number of active monthly Instagram users from January 2013 to June 2018. Retrieved on 3 August 2018 from https://www.statista.com/statistics/253577/numberof-monthly-active-instagram-users/.

Statistica (2018b). Leading countries based on number of Instagram users as of July 2018. Retrieved on 3 August 2018 from https://www.statista.com/statistics/578364/countrieswith-most-instagram-users/.

Stockwell, G. (2013). Technology and motivation in English-language teaching and learning. In E. Ushioda (Ed.), International perspectives on motivation: Language learning and professional challenges (pp. 156-175). Basingstoke, UK: Palgrave Macmillan.

Taskiran, A. Gumusoglu, E. K., \& Aydin, B. (2018). Fostering foreign language learning with Twitter: Reflections from English Learners. Turkish Online Journal of Distance Education, 19(1), 100-116.

Ushioda, E. (2011). Language learning motivation, self and identity: Current theoretical perspectives. Computer Assisted Language Learning, 24(3) 199-210.

Ushioda, E. (2013). Motivation matters in mobile language learning: A brief commentary Language Learning \& Technology, 17(3), 1-5. 


\section{Appendix A}

The potentials of Instagram as a MALL Tool Survey

\section{A) Please fill out the following background information}

1. Age:

2. Gender: Male ___ Female

3. Country of origin:

4. Mother tongue (first language):

5. Year in college:

_Freshman _Sophomore _Junior _ Senior _MA _ _ PhD Other

6. a. Major (e.g., TESOL, Engineering):

b. Minor:

7. Please circle your proficiency level for English in the following areas.

\begin{tabular}{lllllll}
\hline & Beginning & & & & \multicolumn{2}{c}{ Advanced } \\
\hline Reading & 1 & 2 & 3 & 4 & 5 & 6 \\
\hline Writing & 1 & 2 & 3 & 4 & 5 & 6 \\
\hline Listening & 1 & 2 & 3 & 4 & 5 & 6 \\
\hline Speaking & 1 & 2 & 3 & 4 & 5 & 6 \\
\hline
\end{tabular}

8. Do you have an Instagram account? Yes _ No

9. What language is your Instagram account in? _ First Language

10. How long have you been using Instagram?

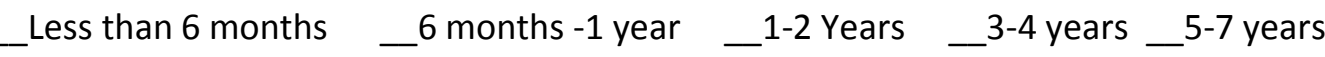

11. How often do you log into Instagram?

Every day _ _-4 Times a Week__once a week_Once a Month Other

12. How many hours do you spend on Instagram per day?

13. What language do you use the most to communicate on Instagram?

First Language _English _ Both first language and English Other

14. Approximately what percentage of your communication on Instagram is in English?

15. Approximately what percentage of your followings is related to language learning?

B) Attitudes towards and perceptions of using Instagram

\begin{tabular}{|c|c|c|c|c|c|c|}
\hline \multicolumn{7}{|c|}{$1=$ Strongly Disagree $6=$ Strongly Agree } \\
\hline 1. Instagram is suitable for educational purposes. & 1 & 2 & 3 & 4 & 5 & 6 \\
\hline 2. Instagram is a good platform to practice writing in English. & 1 & 2 & 3 & 4 & 5 & 6 \\
\hline 3. Instagram is a good platform to read in English. & 1 & 2 & 3 & 4 & 5 & 6 \\
\hline 4. Instagram is a good platform to develop English communication skills. & 1 & 2 & 3 & 4 & 5 & 6 \\
\hline 5. Instagram is a good platform to overcome language mistakes. & 1 & 2 & 3 & 4 & 5 & 6 \\
\hline 6. Instagram is a good platform to learn new words in English. & 1 & 2 & 3 & 4 & 5 & 6 \\
\hline 7. Instagram is a good platform to improve English grammar knowledge. & 1 & 2 & 3 & 4 & 5 & 6 \\
\hline 8. Instagram is a good platform to improve overall English skills. & 1 & 2 & 3 & 4 & 5 & 6 \\
\hline 9. Instagram is a good platform to reach authentic English materials. & 1 & 2 & 3 & 4 & 5 & 6 \\
\hline 10. Instagram makes learning English more interesting. & 1 & 2 & 3 & 4 & 5 & 6 \\
\hline 11. Instagram makes learning English easier. & 1 & 2 & 3 & 4 & 5 & 6 \\
\hline 12. Instagram increases my motivation to communicate using Eng & 1 & 2 & 3 & 4 & 5 & 6 \\
\hline 13. Instagram increases my motivation to read English materials. & 1 & 2 & 3 & 4 & 5 & 6 \\
\hline 14. Instagram increases my motivation to write in English. & 1 & 2 & 3 & 4 & 5 & 6 \\
\hline 15. Instagram encourages me to spend more time learning En & 1 & 2 & 3 & 4 & 5 & 6 \\
\hline
\end{tabular}


CONTEMPORARY EDUCATIONAL TECHNOLOGY, 2019, 10(3), 309-323

DOI: https://doi.org/10.30935/cet.590108 - TYPE: Research Article

C) Open-ended questions:

1. As an experienced user of Instagram for language learning purposes, could you briefly describe your experiences?

2. Do you think Instagram can be a useful pedagogical tool in English classrooms? Why? Or why not?

3. What are your opinions regarding learning English through such social networking platforms?

\section{Appendix B}

Dendrogram

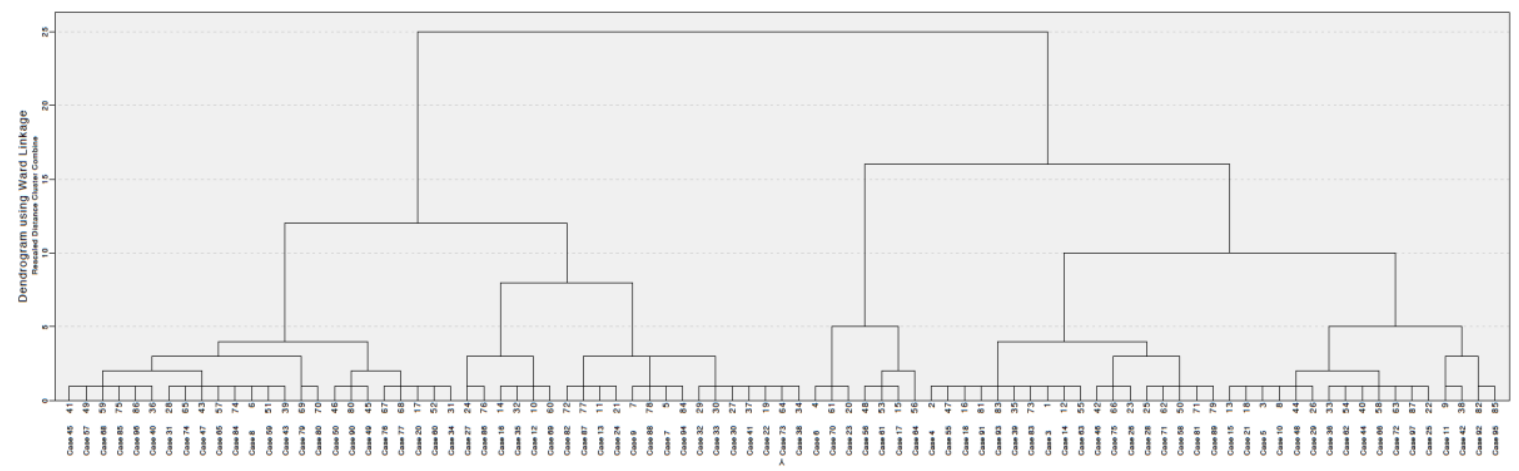

Correspondence: Talip Gonulal, Assistant Professor, Department of Foreign Languages

Teaching, Faculty of Education, Erzincan Binali Yildirim University, Erzincan, Turkey 